\title{
The Concept and Connotation of Talents Cultivation in Landscape Architectural Design
}

\author{
Meng Xiaopeng \\ Xiamen University Tan Kah Kee College \\ Zhang Zhou, China \\ mengxp1995@xujc.com
}

\begin{abstract}
The talents cultivation with special characteristics of landscape architecture major should can create "artistic landscape architecture" and achieve the concept of engineering art in their work, so as to effectively meet the needs of social environmental construction. Therefore, the cultivation of the talents in this major comes from the three-dimensional development of social responsibility, cultural accumulation, and learning ability. The cultivation of landscape architecture design talents should focus on three abilities: solving the project contradictions in different topics, designing rationally and sensitively, and cooperating with teams and rapidly integrating into the large design project.
\end{abstract}

Keywords-Landscape architectural design; Talents cultivation; Concept; Connotation

\section{THE MAJOR ORIENTATION OF LANDSCAPE ARCHITECTURE}

Architecture is a threshold of human civilization. With the development of human society, it imprints every step of the process of civilization. Compared with the long history of architecture, "landscape (garden) architecture", as a relatively independent subject, has been separated from architecture for only more than 100 years. "In 1863, the Park Council of New York has entrusted the official design bookmark to Omster, an architect of the landscape, which symbolized the official birth of the architects of the landscape and the architecture of the landscape. In 1899, the American Society of Landscape Architects (ASLA) was founded in New York. In 1900, Omster's son taught landscape architecture as a course for the first time at Harvard."[1] In mainland China, the history of the landscape environment, as an independent discipline, is even shorter. It is just after the 1990s, when social wealth has accumulated to a certain extent and freed itself from the long spiritual shackles, the environment can be isolated from architecture as an appreciable and enjoyable work of art. Thus, the "Environmental and Art" major has been set up in many colleges and universities. Its main orientation lies in the exploration of indoor and outdoor space environment landscape art, in addition to the building design. But after 21th century, with the rapid development of economy, and the improvement of people's need and understanding of environmental and art, they need more blending and dialogue between architecture and environment, and in the area of close integration of architecture and environment, architectural design and environmental design, as usual in the past, work one after another, which often can not achieve the best results. Thus, more exchange of the two movements at the same time is needed. Therefore, landscape (environment + architecture). $\rightarrow$ Landscape architecture is bound to be increasingly independent and perfect with the development of society and become an integrated interdisciplinary field across multiple disciplines. It is based on the needs of the current situation of environmental design in China and the recognition of landscape architecture subject prospects, clearly defining the basic concept of landscape architecture design education is of great significance for both the development of landscape architecture education and industry prospects.

A brief definition for this science, outlined by the American Society of Landscape Architects, is "an art of designing, planning, land management, and arranging natural and artificial elements in order to make the environment the ultimate objective that can be used and enjoyed, with the means of using cultural and scientific knowledge, and considering the use and management of resources.". This definition has also become our major orientation of "landscape and architecture design direction". In terms of the content involved in the field of the major, in addition to the nine plannings identified by the American Society of Landscape Architects, such as landscape design, master plan or base planning, cities and towns planning, regional landscape planning, park and leisure site planning, ecological planning design, historical conservation and rehabilitation, the social and behavioral aspects of landscape design, we have added one item: architectural design with environmental characteristics and artistic expression value, according to the characteristics and needs of Chinese architectural environment. These ten contents have become the basis of the major teaching orientation of the design direction of "landscape architecture". 


\section{The Cultivation PRINCIPLE OF TALENTS Guided By PRACTICE}

From the above orientation of landscape architecture major, it can be seen that landscape architecture is more closely related to society, economy, culture, ecology and of greater social and environmental influence than architecture because it pays more attention to the management of social resources and the utilization of environmental resources. Therefore, on the basis of perfect theoretical education, we also emphasize the practicality of education. The practical education of landscape architecture is not only the demand of landscape architecture education itself, but also an important direction of teaching and training in Tan Kah Kee College of Xiamen University, which has the specialty of practical teaching.

\section{A. Cultivating Students' Healthy and Complete Aesthetic Consciousness and Thinking Habit}

Gadamer tells us in Truth and Method: "Art is also an important way to reveal truth. This truth can be different from the truth of science, but it is not lower than the truth of science"[2]. Thus, it can be seen that art, as a truth, can not be expressed in exact equations as science, but it is not merely an expression and experience of a simple personal perception, and it must have a relatively stable basis of judgment. And the criterion should be the highest goal of all art: truth, goodness and beauty. That is to say, the form of architecture and landscape art shows the care and love to society, human beings and nature. Therefore, the most important foundation of landscape architecture education is to enable students to establish a healthy and complete aesthetic consciousness and value judgment ability in the landscape architecture industry in various design trends and chaotic construction phenomena.

Should landscape architecture art, like any other art, be an expression of the artist's self-feeling, and should the main goal be to get a strong experience from the viewer? Whatever the outcome is of this debate, there is an undeniable and fundamental difference between landscape architecture art and other art: the artistic expression of any other artists can follow suit and possess no public resources. The audience has a choice of acceptance or rejection. Therefore, no matter whether the works of art are accepted by the society, neglected or sought after, the results will be borne by the artists themselves, and will not have an essential impact on society and the environment. However, landscape architecture art is a practical art with the ability to occupy huge social resources and deploy social behavior. When artists show their art, at the same time, the architect's artistic results are borne by others or the society, and there are mandatory requirements on other people's social behavior and way of life. Besides, it has a huge impact on the social environment, ecological environment after the completion. Therefore, economic, cultural, social, psychological and artistic conception and expression, must be part of the landscape architecture. Therefore, we pay more attention to cultivating students' comprehensive and accurate cognition of the characteristics of architectural art (especially the landscape architecture art), and on this basis to establish a healthy and complete aesthetic consciousness and thinking habits. Only in this way can we have the correct and rational judgment, can calmly and comprehensively understand, judge the various trends of thought and phenomena in the development of landscape architecture art, and make clear the direction of our own efforts.

\section{B. Establishing A Sense of Social Responsibility and A Sense of Professional Honor}

"Architects are people who can dream of a beautiful world and who can design paths to reach their goals." [3]This is a bright career definition. Landscape architecture can have a great impact on the society and environment, so the architect should also bear the huge responsibility. In reality, however, architects in China work in a way that takes little risk: "using others' land, spending others' money, so the results, good or bad, needs to be borne by the owner himself." From this, we can also understand why many so-called international "masters" can freely show their "artistic imagination" on the land of China. For the many irrational situations that Chinese architecture has presented since the reform and opening up, as Secretary General of the American Planning Association and academician registered planner, JeffreyL. Soule, who has been involved in urban planning and design in China for more than a decade, pointed out: "Chinese officials who lack training or experience in urban design, often mix modern design with domineering and eccentric designs. As a result, some foreign architects who have been rejected or mocked by their own countries for their childish designs have found a sympathetic audience in China. However, some domestic scholars and experts, often benefiting from their economic relations with these outsiders, to improve their political and professional status, are unable to make an objective and honest voice to suppress the blind movement of such a system." Thus, it can be seen that the present situation in the field of Chinese architecture is not only an artistic aesthetic issue, but also a complex social phenomenon that is intertwined by politics, economy and culture. It is because of the extensive and farreaching impact of the architectural field that landscape architects, should be like doctors, have a basic sense of social responsibility, as well as a sense of professional honor brought about by social responsibility.

The gathering house, hailed by architectural critics as "modernist funeral," bombed in July 15th, 1972 in St. Louis, Pruitt Igoe, also illustrates that even if it is made by famous architects and recognized the winning works by the architectural industry, without a basic concept of social and humane care and responsible thinking on social issues, it still can not escape the fate of abandonment. Therefore, from the aspect of the architect's social influence ability, the architect must realize the function of his artistic expression to the society, environment, culture, people's psychology and so on. "There is a need to confine the strong desire expressed by oneself to the interests of the whole." [4]Therefore, the cultivation of students with a clear sense of social responsibility and professional honor is the throughout basic principles in our landscape architecture education. The essence of landscape architecture design is to pursue the harmony between man and nature, the balance between modern and traditional, the blend of science and technology and culture. Therefore, in the process of vocational education, cultivating students' healthy and complete professional aesthetic consciousness and thinking 
habits can bring students mature and calm ability of judgment and analysis. And the social responsibility and professional honor will enable the landscape architects to experience a great sense of achievement, so as to explore the enthusiasm and motivation in the professional road.

\section{Take the Artistic and Cultural Accumulation as the Connotation Characteristic}

In the brief definition that the American Society of Landscape Architects has outlined for this science, we can see that landscape architecture is ultimately an art product capable of providing different functions and activities. The artistic expression of the design conception is the final result of the professional display, so the artistic creation and the artistic display will inevitably become the benchmark of the landscape architecture.

For the understanding and accumulation of art and culture, we hope to complete in both the breadth and depth of them. In 1898, Mr. Zhang Zhidong put forward the theory of "Chinese Body and Western Usage": "Chinese learning is internal learning, western learning is external learning. Chinese learning is for cultivation of the body and mind, the western culture is for things." This idea is equally instructive for the development principles of our education today. In terms of breadth, it is about quantity, it suggested learning all kinds of art information both at home and abroad timely with large quantity, especially learn and absorb the "western learning", which is active in artistic conception and advanced in technical expression and also an important means for "things". This problem is relatively easy to accomplish for students under the condition of diversification of media and mode of expression. In terms of depth, it is about quality, it hoped that the students will be deeply and meticulously familiar with a cultural system, especially the understanding and grasp of Chinese traditional culture, which is the basis of our "cultivation of body and mind". Chinese traditional culture is extensive and profound and has a relatively stable and long-term influence in the land of China. It can construct a steady ideological framework and artistic feelings in the modern and chaotic social environment, so that we can enrich our hearts and have a far-reaching vision. The creation of landscape architecture art can be developed on a solid and profound basis, which will become the foundation of the future Chinese landscape architects in the market development. This problem, needs a rather long accumulation process. In addition to the extra-curricular efforts of students, we gradually guide them in the teaching and promote the understanding and understanding of traditional Chinese culture by setting curriculum in different grades.

\section{CONCLUSION}

Universities characterized by practical education should have a high educational orientation, concern for human beings, advance social progress, and serve the country, which is the mission of university. It not only because the students cultivated by it can directly participate in the process of social development and have profound social influence, but also because if the education goal only for adapting to the reality society, the education way also easy to walk into the pure vocational skill training direction, it causes that the student lack the rise space for ability and the education patterns. Especially for the landscape architecture teaching, which is closely related to many aspects of the real society and has far-reaching influence, it is even more necessary to continuously explore the intermingling and pushing forward of the traditional culture and the needs of the times on the basis of profound Chinese traditional culture. Therefore, we can cultivate the talent in a higher level of humanistic spirit, with a profound regional characteristics of the practice capacity, thus in an advantageous position in the international competition.

\section{REFERENCES}

[1] Yang Beifan, Zhang Bin, eds. Urban Design and Environmental Art [M].Tianjin: Tianjin University Press, 2002.4.

[2] Schumer. A Collection of Schumer's Architectural Art [M] .Beijing: machinery Industry Press, March 4, 2003. (In Chinese)

[3] Zhu Fuyi. The significance of Architectural Education background in Landscape Design. Collection of Architectural and Cultural theories (8th National Symposium on Architecture and Culture, June 2006).

[4] Http: r. P. P. P. Pcpop. com / 061108 / 269198. Html: traditional buildings give way to power-600 cities have largely lost their individuality. 